\title{
Artificial Pacing in Management of Complete Heart Block Complicating Acute Myocardial Infarction
}

\author{
B. W. LASSERS, * M.B., M.R.C.P., M.R.C.P.ED. ; D. G. JULIAN, $\dagger$ M.A., M.D., M.R.C.P., M.R.C.P.ED., M.R.A.C.P.
}

Brit. med. F., 1968, 2, 142-146

Complete heart block complicates approximately 6 to $8 \%$ of cases of acute myocardial infarction and is associated with a high mortality (Julian et al., 1964 ; Meltzer, 1967 ; Siddons and Sowton, 1967). In some patients death may be due to coexistent severe myocardial damage rather than to a complication of heart block itself, but in others it can be attributed to ventricular asystole or severe bradycardia. In the latter cases control of the cardiac rhythm by drugs or artificial pacing may be effective and life-saving. The purpose of this communication is to review the first 51 cases of complete heart block complicating acute myocardial infarction admitted to the coronary care unit of the Royal Infirmary, Edinburgh, with particular reference to the role of pacing in the management of this disorder of conduction.

\section{Patients}

The 51 patients consisted of all those with complete interruption of atrioventricular (A.V.) conduction with independent atrial activity admitted during the first 17 months of the coronary care unit. Patients with A.V. dissociation of the interference type, patients with transient complete heart block after D.C. shock for ventricular fibrillation, and patients with atrial as well as ventricular asystole have not been included. The clinical diagnosis of acute myocardial infarction was confirmed by electrocardiographic and serum enzyme changes in 49 patients. The diagnosis was regarded as established if : (a) pathological $\mathrm{Q}$ waves appeared on the E.C.G. accompanied by an elevation of the $\mathrm{S}-\mathrm{T}$ segment and subsequent inversion of the $\mathrm{T}$ wave (World Health Organization, 1959); (b) there were changes in the $S-T$ segment and $T$ wave suggestive of infarction accompanied by a significant rise in the serum aspartate aminotransferase ( $>50$ Reitman and Frankel units) and serum creatinine kinase $(>80$ i.u.) ; or $(c)$ there was left bundle-branch block accompanied by similar enzyme changes (Lawrie et al., 1967). The diagnosis was also confirmed at necropsy in 20 of these patients and in the two others in whom full electrocardiograms had not been recorded.

\section{Methods}

The coronary care unit of the Royal Infirmary, Edinburgh, and its system of monitoring have been described elsewhere (Lawrie et al., 1967). Initially bipolar pacing electrodes (U.S.C.I. No. 5651, size 5F) were inserted from an antecubital vein, but the percutaneous supraclavicular subclavian vein route proved superior and was subsequently used. Percutaneous transthoracic electrodes (Elecath ${ }^{1}$ ) were inserted direct into the heart in patients in whom there was inadequate time for introduction of transvenous electrodes. At first patients were transferred to the cardiac laboratory for insertion of electrodes under fluoroscopic control, but later a portable image intensifier (Cardiovision ${ }^{2}$ ) was designed for use in the coronary

\footnotetext{
* Registrar in Cardiology, Royal Infirmary, Edinburgh 3.

t Consultant Physician, Royal Infirmary, Edinburgh 3 ; Senior Lecture in Medicine, University of Edinburgh.

Electro-Catheter Corporation, 932 East Elizabeth Avenue, Linden, New

Watson \& Sons Ltd., East Lane, Wembley, Middlesex.
}

care unit at the patient's bedside. Right ventricular outflow tract pacing was not employed and all electrodes were positioned with the tip at the apex of the right ventricle. Continuously discharging variable-rate, variable-current pulse generators incorporated in the Sanborn Visomonitor were originally used for pacing. The minimum current of $5 \mathrm{MA}$ obtainable with this unit was found to be above the contraction threshold in all patients in whom the electrode was properly pusitioned. Because of the risk of pacemaker-induced ventricular fibrillation under these circumstances, this apparatus was abandoned. Devices battery-operated, continuously discharging variable-voltage units ${ }^{3}$ were substituted and employed until June 1967, when Devices ventricular demand pacemakers were made available.

Initially electrodes were inserted in all patients with seconddegree A.V. block as well as all patients with complete heart block. Later this policy was modified to include all patients with complete bundle-branch block. The presence of complete heart block was not regarded as an indication for instituting pacing unless ventricular asystole occurred or a low cardiac output was suggested by clinical evidence of diminished cerebral and skin blood flow. Pacing was performed at twice the contraction threshold energy and at the slowest rate which produced an increase in blood pressure accompanied by clinical evidence of improved cerebral and skin circulation. When continuously discharging pacemakers were used pacing was discontinued as soon as A.V. conduction returned. When ventricular demand instruments were employed the pacemaker rate was set below the patient's own rate when sinus rhythm returned. Electrodes were withdrawn after 72 hours had elapsed without heart block of greater than first degree, and after a further 24 hours the patient was transferred to a general medical ward.

\section{Results}

Age, Sex, and Deaths.-There were 36 male and 15 female patients. The mean age was 61.3 years, with a range of 31 to 87 years. The mean age of the male patients was 61 years, and that of the females 65.5 years. Of the 51 patients 24 died $(47 \%)$. The mean age of the patients who died was 65.2 years compared with 59.8 years for the survivors.

Time of Onset.-Both the time of onset of symptoms of infarction and the time of onset of complete heart block were known with reasonable accuracy in 48 of the 51 patients (Fig. 1). Seventeen patients $(35 \%)$ had syncope as an initial symptom of infarction and electrocardiographic confirmation of complete heart block within the succeeding three hours. Forty-one patients $(85 \%)$ developed complete heart block within 48 hours of the onset of symptoms of infarction.

Duration.-Complete heart block was transitory, and normal A.V. conduction returned in all 27 survivors. The duration of complete heart block in those patients in whom the time of its onset was accurately known ranged from less than a minute to 7.7 days (mean 2.5 days).

Preceding Disorders of Conduction, Rate, and Rhythm.Twenty-two patients had complete heart block on admission

\footnotetext{
s. J. Reynolds Ltd., 3 Compton Road, Winchmore Hill, London N.21.
} 
to the unit. All of the remaining 29 patients had some disorder of conduction, rate, or rhythm detected before they developed complete heart block (Table I). In 25 of them the disorder was one of conduction, the most common being complete bundle-branch block and second-degree A.V. block. Two patients had atrial fibrillation and atrial flutter respectively with a slow ventricular response in the absence of digitalis therapy, indicating advanced A.V. block.

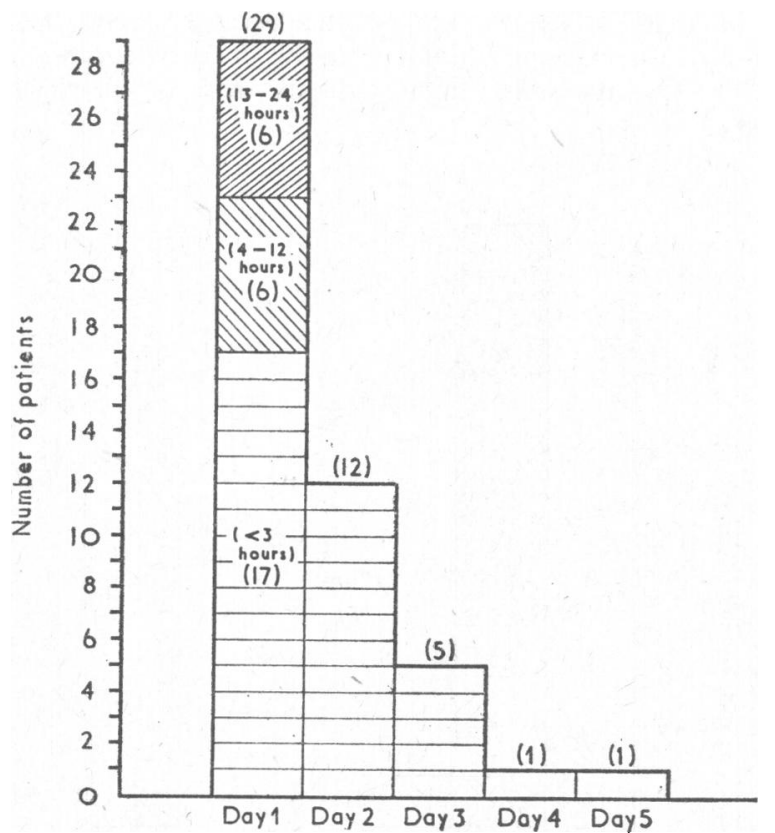

FIG. 1.-Time of onset of complete heart block after development of symptoms of acute myocardial infarction.

TABLE I.-Disturbances of Conduction, Rate, and Rhythm Preceding the

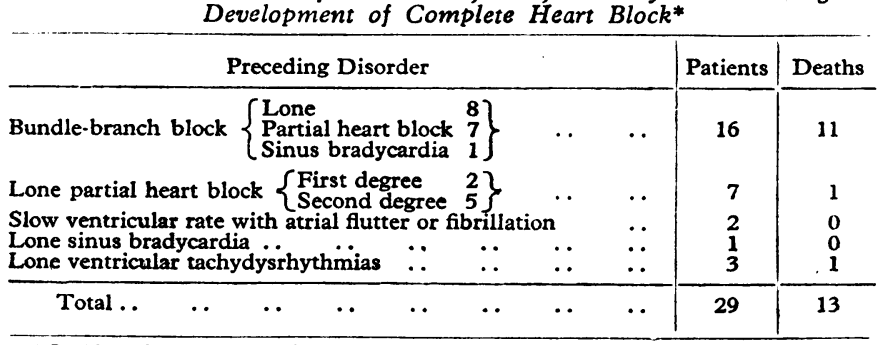

* In 29 patients who developed complete heart block while being monitored.

\section{Prognostic Features}

Certain clinical and electrocardiographic features were associated with a high mortality, though the natural mortality was modified by treatment. The prognosis was worst when one or more of the following clinical features were present: cardiogenic shock, left ventricular failure, right ventricular failure, Stokes-Adams attacks, and depressed mental function.

The site of infarction and the duration of the QRS complex in complete heart block were of considerable prognostic significance. Involvement of the anterior wall of the heart either with or without concomitant inferior involvement was associated with a high mortality, while isolated inferior infarction carried a better prognosis. Isolated involvement of the anterior wall occurred in 11 patients, of whom 10 died. Combined involvement of anterior and inferior walls occurred in seven patients and five died. Isolated inferior infarction occurred in 33 patients and only nine $(27.3 \%)$ of these died.

The duration of the QRS complex in complete heart block was of prognostic significance in patients with isolated inferior wall infarction, but of little significance in patients with anterior involvement. Thus in inferior wall infarction with a broad QRS complex of complete bundle-branch block type five out of six patients died compared with only 3 out of 26 with a QRS of less than 0.12 second. However, in infarction involving the anterior wall (with or without concomitant inferior infarction) 11 out of 13 patients with a broad complex and four out of five patients with a narrow complex died.

\section{Experience with Pacing (Table II)}

Electrodes were not inserted in four patients. Two of these died soon after admission to the unit and before electrodes could be inserted. Electrodes were not inserted electively in the remaining two patients early in the series. One of these, who survived, had complete heart block for a few seconds during a period of vomiting. In the other, who died, an electrode was not inserted because severe cardiogenic shock had been present for some hours before the onset of complete heart block.

TABLE II.-Experience with Pacing in Complete Heart Block Complicating Acute Myocardial Infarction

\begin{tabular}{|c|c|c|c|c|c|c|c|c|c|}
\hline \multicolumn{8}{|c|}{ Type of Electrode } & \multirow{2}{*}{$\begin{array}{c}\text { Patients } \\
42 \\
14 \\
28 \\
5^{*} \\
4\end{array}$} & \multirow{2}{*}{$\begin{array}{r}\text { Deaths } \\
0 \\
16 \\
5 \\
3 \\
\end{array}$} \\
\hline $\begin{array}{l}\text { Transveno } \\
\text { Not emp } \\
\text { Employe } \\
\text { Transthora } \\
\text { Electrode n }\end{array}$ & $\begin{array}{l}\text { s en } \\
\text { oyed } \\
\text { ic } \\
\text { ic in. }\end{array}$ & 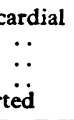 & $\begin{array}{l}\cdots \\
\cdots \\
\cdots\end{array}$ & $\begin{array}{l}\cdots \\
\cdots \\
\cdots \\
\cdots\end{array}$ & $\begin{array}{l}\cdots \\
\cdots \\
\cdots\end{array}$ & $\begin{array}{l}\cdots \\
\therefore \\
\therefore\end{array}$ & $\begin{array}{l}\cdots \\
\cdots \\
\cdots\end{array}$ & & \\
\hline Total & .. & . & . & $\cdots$ & .. & .. & . & 51 & 24 \\
\hline
\end{tabular}
pacing and were replaced by transvenous electrodes.

Percutaneous transthoracic electrodes were inserted direct into the heart in seven patients. Three of these were admitted to the unit moribund with ventricular asystole, and transthoracic electrodes produced neither electrical nor mechanical response. A ruptured ventricle, not due to the electrode, was demonstrated at necropsy in two of these three patients. The remaining four patients developed ventricular asystole while being monitored in the unit. In two of them transthoracic electrodes produced adequate pacing and allowed time for insertion of transvenous electrodes, but both subsequently died. The remaining two patients who developed ventricular asystole while being monitored died despite adequate electrical capture of the ventricles by the transthoracic electrode, but without apparent mechanical effect.

Transvenous endocardial electrodes were introduced in $\mathbf{4 2}$ patients, 40 of them without prior insertion of transthoracic electrodes. In 14 the development of complete heart block was not associated with deterioration in the clinical state, and pacing was not used. All 14 returned to sinus rhythm and survived. Artificial pacing was used in 28 patients, of whom 12 survived.

Eight of these 12 survivors were paced for Stokes-Adams attacks due to ventricular asystole and for bradycardia associated with depressed mental function, poor peripheral circulation, and hypotension occurring during complete heart block. In seven patients pacing produced a rapid and marked improvement in mental state, skin circulation, and systemic blood pressure. The eighth patient survived despite the fact that pacing had to be discontinued because it produced angina and dyspnoea.

In the ninth survivor complete heart block with bradycardia and periods of ventricular asystole alternated with paroxysms of nodal tachycardia at 115 per minute. Pacing at 120 per minute suppressed the tachycardia and abolished the attacks of asystole. Despite the rapid ventricular rate, the blood pressure rose and there was considerable improvement in mental function and skin circulation. The tenth and eleventh survivors, who had not required pacing during complete heart block, did so when 2:1 block developed and their ventricular rates fell from more than 50 per minute to 30 . Pacing abolished faintness and hypotension in one and chest pain in the other. 
The twelfth survivor was admitted to the unit with complete heart block and a ventricular rate of 52 per minute. She was semiconscious, with the clinical features of cardiogenic shock and biventricular failure. Pacing at 100 per minute produced an immediate improvement in the mental state. The systolic blood pressure rose from 70 to $115 \mathrm{~mm}$. $\mathrm{Hg}$ and within 12 hours the signs of ventricular failure had disappeared. Thus in 11 of the 12 survivors pacing was thought to have been of considerable benefit by abolishing Stokes-Adams attacks and by increasing cardiac output.

\section{Complications Associated with Pacing (Table III)}

The most serious complication associated with pacing in the present series was ventricular fibrillation, which occurred in seven patients. In one patient it was mechanically induced during introduction of the electrode but responded to immediate defibrillation and the patient survived. In two patients recurrent episodes of ventricular fibrillation occurred during pacing. The first, who died, had asystole when pacing was discontinued and ventricular fibrillation whenever pacing was attempted. The second, who survived, continued to have recurrent ventricular fibrillation after A.V. conduction had returned and the electrode had been removed. In the four remaining patients ventricular fibrillation occurred after A.V. conduction had returned and competition developed between the patient's own rhythm and that of the pacemaker. Two of them died of ventricular fibrillation and their deaths were probably pacemaker-induced. Both patients had, however, required pacing for asystole and severe hypotension and would probably have died without it. Three of the instances of ventricular fibrillation associated with competition occurred with the Sanborn instrument and one with the Devices continuously discharging pacemaker. In the latter case competition had been misinterpreted as a failure of electrical capture and the pacing voltage had been increased to a relatively high level.

TABLE III.-Complications Associated with Pacing in Acute Myocardial

\begin{tabular}{|c|c|c|c|c|c|c|c|}
\hline \multicolumn{6}{|c|}{ Complication } & \multirow{2}{*}{$\frac{\text { Patients }}{7}$} & \multirow{2}{*}{$\frac{\text { Deaths }}{3}$} \\
\hline Ventricular fibrillation & $\left\{\begin{array}{l}\text { Mechanic } \\
\text { Recurren } \\
\text { Competit }\end{array}\right.$ & $\begin{array}{l}y \text { in } \\
\text { lurir } \\
\text { tur }\end{array}$ & $\begin{array}{l}\text { ced } \\
\text { pacing }\end{array}$ & $\left.\begin{array}{l}1 \\
2 \\
4\end{array}\right\}$ & $\cdots$ & & \\
\hline $\begin{array}{l}\text { Faulty electrical connex } \\
\text { Pneumothorax } \\
\text { Myocardial perforation } \\
\text { Atrial flutter } \\
\text { Angina induced by paci } \\
\text { Late recurrence of com }\end{array}$ & $\begin{array}{ll}\text { sion } & \\
\cdots & \because \\
\ddot{\text { plete }} & \text { block }\end{array}$ & $\begin{array}{l}\ldots \\
\ldots \\
\cdots \\
\ldots\end{array}$ & $\begin{array}{l}\because \\
\because \\
\because \\
\cdots\end{array}$ & $\begin{array}{l}\because \\
\because \\
\because \\
\cdots\end{array}$ & $\begin{array}{l}\because \\
\because \\
\because \\
\cdots\end{array}$ & $\begin{array}{l}1 \\
1 \\
3 \\
1 \\
1 \\
1 \\
1\end{array}$ & $\begin{array}{l}1 \\
0 \\
0 \\
0 \\
0 \\
0\end{array}$ \\
\hline Total .. & .. & .. & .. & -. & .. & 15 & 4 \\
\hline
\end{tabular}

In one patient death was due to failure to respond to pacing which may have been caused by a faulty electrical connexion. In a further patient difficulty was encountered in locating the subclavian vein during insertion of the electrode, and a small pneumothorax, which did not require treatment, was produced. In three patients myocardial perforation was suspected because of the development of localized pericardial friction. Pacing became intermittent in two of them and the contraction threshold was found to have increased. This was corrected in both cases by withdrawing the electrode slightly. In another patient atrial flutter developed at the moment the electrode was withdrawn from the right ventricle into the atrium, and D.C. shock was required to restore sinus rhythm. In a further patient pacing produced angina and dyspnoea and had to be discontinued. There was one late recurrence of complete heart block 7.5 days after the return of normal A.V. conduction. An electrode was reinserted and the patient survived. Another patient died suddenly in a general medical ward 13 days after the return of normal A.V. conduction, but the cause of death was not established. Though local skin sepsis occurred around the site of electrode insertion in several patients, there was no instance of septicaemia.

\section{Deaths}

Fig. 2 shows that when death occurred it usually did so soon after the onset of complete heart block. Seven deaths (29\%) occurred within two hours of the onset of complete heart block and $20(83 \%)$ within 72 hours. The commonest mode of death was cardiogenic shock. Eleven patients died in this manner. One of these 11 was moribund on admission and died before an electrode could be inserted, and in a further patient an electrode was not inserted because severe shock had been present for some hours before the onset of complete heart block. The remaining nine patients died of shock despite pacing.

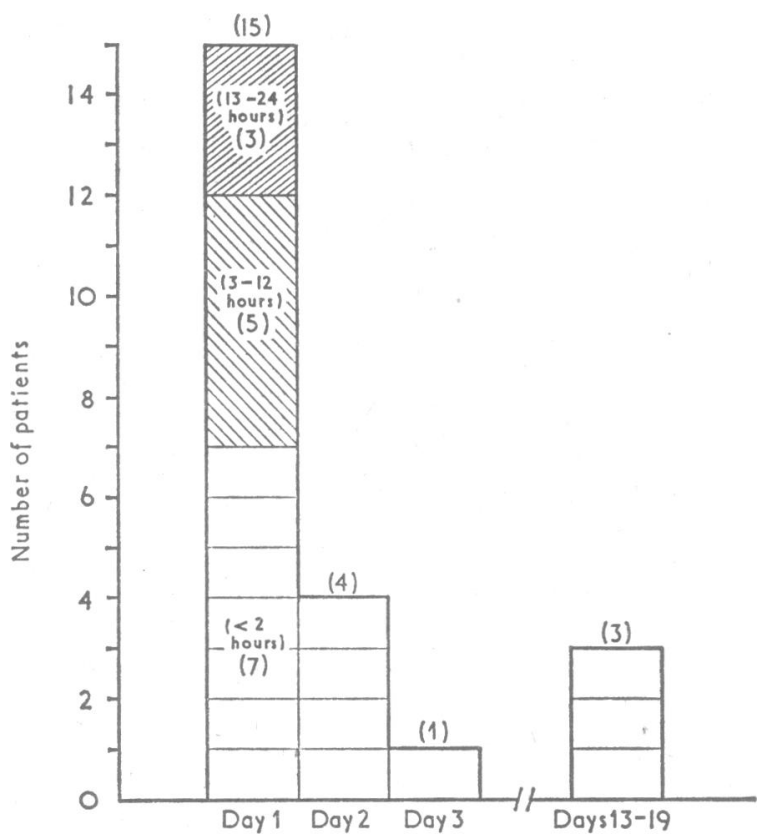

Fig. 2. - Time of death after onset of complete heart block in 23 of the 24 deaths. Onset of complete heart block not known in one patient.

Complete heart block of sudden onset with ventricular asystole accounted for six deaths. One of these occurred before an electrode could be inserted, and in another failure to pace was probably due to an electrical fault. Two patients developed asystole while transvenous electrodes were in situ, but pacing produced neither electrical nor mechanical response. The remaining two patients with complete heart block of sudden onset had severe cardiac failure and had been on large doses of lignocaine for ventricular tachydysrhythmias. Transthoracic electrodes were introduced and electrical pacing of the heart was achieved, but in both cases there was no apparent mechanical response.

The remaining deaths were due to ventricular fibrillation (2), myocardial rupture (3), pulmonary embolism (1), and late unexplained death (1).

Necropsies were performed in 22 of the 24 deaths. Table IV shows the findings in the coronary arteries and the location of the infarction in these cases.

TABLE IV.-Necropsy Findings in 22 Patients with Complete Heart

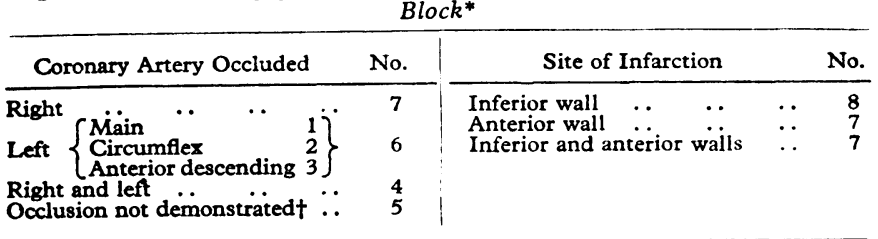

- Necropsy performed in 22 of the 24 deaths in the series.

+ All five had severe atheromatous narrowing of all three major arteries, but no definite occlusion was demonstrated. 


\section{Discussion}

Death in patients with complete heart block may be due to one or more of a number of factors: ventricular asystole, the haemodynamic consequences of bradycardia, and the severe myocardial damage which often coexists. A substantial proportion of deaths are not due to the heart block itself, as many of them occur despite effective pacing or after the return of normal A.V. conduction (Julian et al., 1964 ; Paulk and Hurst, 1966 ; Parsonnet et al., 1967). However, pacing may be expected to prevent those deaths which are the result of asystole or bradycardia. Various techniques of pacing have been employed for this purpose.

External transcutaneous pacemaking, which has been used by Zoll (1952) and Levowitz et al. (1960), is usually ineffective in the treatment of asystole in myocardial infarction (Lown, 1967), and is unsuitable for the management of bradycardia because of pain and skin burns (Escher, 1967). The direct percutaneous insertion of an electrode into the heart has proved effective in some cases, including two in the present series. However, because it is usually employed only when the patient is in extremis, it is difficult to assess the potential of this method. With direct percutaneous insertion there is a risk of producing pneumothorax, pericardial tamponade, and coronary artery damage.

The most widely used technique of pacing has been that of introducing an electrode through a peripheral vein. Various sites have been utilized, including arm veins (Harris and Bluestone, 1966 ; Siddons and Sowton, 1967), external jugular veins (Paulk and Hurst, 1966 ; Parsonnet et al., 1967), femoral veins (G. Sloman, personal communication, 1967), and percutaneously into the subclavian vein (Yoffa, 1965; E. J. Epstein, personal communication, 1967). When an arm vein is used a relatively stable electrode position can be achieved only by completely immobilizing the patient's arm. This causes discomfort to the patient and impedes nursing. The external jugular vein route is of ten time-consuming and technically difficult (Paulk and Hurst, 1966 ; Parsonnet et al., 1967). The percutaneous supraclavicular subclavian vein technique has in most cases proved to be rapid and simple, and, like the external jugular route, has the advantage of providing electrode stability. Its principal hazard is the production of a pneumothorax as occurred in one patient in the present series.

\section{Position of Electrode}

A stable and effective electrode position can be achieved reliably only by fluoroscopy. In most hospitals this requires the potentially hazardous transfer of the patient to and from a cardiac laboratory. Because of this danger techniques have been evolved for the blind insertion of electrodes with intracardiac electrographic control with either U.S.C.I. 5F electrodes or special float-in electrodes (Kimball and Killip, 1965; Siddons and Sowton, 1967). This technique is not always successful even in skilled hands and the risk of subsequent dislodgement of the electrode is high (Frei et al., 1966). By employing a portable image intensifier especially designed for use in coronary care units these difficulties can be avoided and the electrode can be positioned accurately and rapidly at the patient's bedside.

Asystole or bradycardia requiring pacing may occur unpredictably either at the onset of complete heart block or at any time during its course. If an electrode is not in place death may ensue before one can be introduced and pacing started. It is advantageous, therefore, to have electrodes in position in all patients who are liable to progress to complete heart block as well as in all those who have already developed complete heart block. Approximately $25 \%$ of patients with complete bundle-branch block (Godman et al., 1968) and $50 \%$ of patients with second-degree block (Lown, 1967) progress to complete heart block. There is therefore a strong case for inserting pacing electrodes in these patients. By contrast, first-degree A.V. block and sinus bradycardia rarely progress to complete heart block without warning from intervening second-degree block (Julian et al., 1964 ; George and Greenwood, 1967), and are not regarded as indications for prophylactic electrode insertion.

There is general agreement that asystole is an indication for pacing, though this may not always be effective (Epstein et al., 1966 ; Paulk and Hurst, 1966 ; Parsonnet et al., 1967). The role of pacing in the management of bradycardia in complete heart block is less easy to define (Epstein et al., 1966). While the cardiac output can be progressively increased as the heart rate is raised to more than 100 per minute by pacing, this is probably accomplished at the expense of increased myocardial work and oxygen consumption. The benefits of an improved systemic circulation must therefore be balanced against these increased demands on the damaged heart. Patients with normal mental function and good skin circulation usually have adequate cardiac outputs and a good prognosis. All 14 of the patients in the present series who were in this category survived without pacing. This experience does not support the contention that all patients with A.V. conduction disturbances in acute myocardial infarction should be paced (Harris and Bluestone, 1966). However, when there is depressed mental function and poor skin circulation, severe reduction of the cardiac output is invariable and pacing at 80 to 90 per minute produces a substantial clinical improvement and increase in cardiac output (Lassers et al., 1968). These features, therefore, provide a valuable clinical guide in deciding which patients require pacing.

\section{Major Risk}

Ventricular fibrillation is the major risk associated with pacing in acute myocardial infarction and occurs in from 5 to $21 \%$ of cases (Paulk and Hurst, 1966 ; Parsonnet et al., 1967). It may be induced mechanically, as it was in one patient in the present series, but it is most commonly the result of competition between the patient's spontaneous rhythm and that produced by the pacemaker. With continuously discharging pacemakers competition is likely to occur. Competition is particularly dangerous in acute myocardial infarction because the fibrillation threshold of the ventricular vulnerable period is reduced (Lown et al., 1967). The risks of a competing stimulus producing ventricular fibrillation are increased when the pacing unit has a minimum energy output which is high relative to the contraction threshold-as it is with the Sanborn Visomonitor unit. These dangers can be substantially diminished by using an apparatus which can supply a stimulus energy only slightly above contraction threshold, and can be almost abolished by using a pacemaker of the ventricular demand type (Siddons and Sowton, 1967).

Complete heart block which has developed during an episode of acute myocardial infarction seldom persists (Friedberg, 1966), and normal A.V. conduction returned in all survivors in the present series. In most reported cases of complete heart block persisting after acute infarction (Cohen et al., 1958; Curd et al., 1963 ; Bruce et al., 1965 ; Harris and Bluestone, 1966 ; Parsonnet et al., 1967), either it has been recognized before the infarction or the previous state of A.V. conduction was unknown (Penton et al., 1956 ; Gilchrist, 1958 ; Friedberg et al., 1964). Normal A.V. conduction usually returns within one week. During this period conduction is often unstable and periods of varying block may alternate with sinus rhyrhm. This is the time that competition is particularly apt to occur unless ventricular demand pacemakers are used. Sudden late deaths may occur up to three weeks after the return of normal A.V. conduction (Epstein et al., 1966 ; Harris and Bluestone, 1966). Although these deaths may have been due to recurrence of heart block the mode of death has usually not been estab- 
lished. Documented late relapses are rare and only one such case was encountered in the present series. The risk of removing electrodes after a period of 72 hours without heart block of greater than first-degree is therefore not great. For this reason the long-term monitoring of patients who have had complete heart block does not seem justified when there is a shortage of facilities for intensive care (Oliver et al., 1967).

\section{Other Methods of Treatment}

The effectiveness of other methods of treatment must be considered in assessing the role of pacing in complete heart block complicating acute myocardial infarction. A variety of drugs have been employed in an attempt to restore A.V. conduction, abolish ventricular asystole, and increase ventricular rate. Corticosteroids have been shown to shorten the P-R interval in myocardial infarction (Dall and Buchanan, 1962), but their effectiveness in abolishing complete heart block has not been established. Mittra (1966) has claimed that a solution of potassium, glucose, and insulin reduces both the duration of complete heart block and the mortality associated with it, but Malach (1967) has shown a higher incidence of increasing heart block in patients who received this solution than in a control group. The sympathomimetic amines-particularly isoprenaline-have been the most effective drugs in the treatment of heart block (Vogel and Brammell, 1967 ; Zoll, 1967). Isoprenaline may protect against repeated attacks of ventricular asystole by arousing or accelerating idioventricular pacemakers (Gale and Enfroy, 1959), and may in this way correct a low cardiac output and hypotension when these are due to bradycardia. However, isoprenaline is of little value once ventricular standstill has developed, and it cannot be used to prevent asystole in patients with conduction defects not associated with bradycardia. In addition isoprenaline may readily induce ventricular tachydysrhythmias.

Pacing has the advantage over drug therapy in that it is immediately effective in controlling the electrical activity of the heart at any given rate. It appears to be no more hazardous than isoprenaline, but does require special apparatus and technical skills. When these are available it is probably superior to drug therapy in treating patients with ventricular asystole and patients in whom bradycardia is responsible for clinical deterioration. This represents a minority of those patients in whom complete heart block complicates acute myocardial infarction; in the majority specific treatment is either unnecessary or unsuccessful.

\section{Summary}

Fifty-one consecutive patients with complete heart block complicating acute myocardial infarction are reviewed with particular reference to the role of antificial pacing in the management of this complication. Complete heart block was present in 22 patients on admission. In 25 of the remaining 29 complete heart block was preceded by some other disorder of conduction-most commonly second-degree A.V. block and complete bundle-branch block.

Transvenous or transthoracic pacing electrodes were inserted in 47 of the 51 patients. The most satisfactory route for insertion of the electrode was found to be the subclavian vein, entered percutaneously. A portable image intensifier permitted fluoroscopy without removing the patient from intensive care. Fourteen of the 47 patients were not thought to require pacing and survived. Twenty-one patients died despite pacing. Sub- stantial clinical benefit was apparent in 11 of the 12 remaining patients in whom pacing was used. The most serious complication of pacing was ventricular fibrillation. In four instances this was the result of competition between the patient's spontaneous rhythm and that of the pacemaker when using continuously discharging pulse generators with high stimulus energies.

It is concluded that in the majority of patients with complete heart block complicating acute myocardial infarction specific treatment is either unnecessary or unsuccessful. In an important minority, however, pacing can ensure immediate and reliable electrical control of the heart rate and thus abolish ventricular asystole and correct the haemodynamic disturbances produced by bradycardia. Since these complications may develop suddenly and unpredictably it is advisable to insert transvenous electrodes in all patients with second-degree A.V. block and complete bundle-branch block as well as in all patients with complete heart block. The principal hazard of pacing in acute myocardial infarction-ventricular fibrillation - can be minimized by using pacemakers of the ventricular demand type.

We thank the physicians in charge for permission to study patients under their care and the medical, nursing, and electrocardiographic staff of the coronary care unit for their co-operation and assistance. In particular we are grateful to Dr. R. M. Marquis and Dr. M. F. Oliver for their advice and criticism. Requests for reprints should be addressed to $B$. W. Lassers, Department of Cardiology, Royal Infirmary, Edinburgh 3.

\section{REFBRENCES}

Bruce, R. A., Blackmon, J. R., Cobb, L. A., and Dodge, H. T. (1963). Amer. Heart 7., 69, 460 .

Cohen, D. B., Doctor, L. R., and Pick, A. (1958). Amer. Heart F, 55,

215. W., et al. (1963). Cardiovasc. Res. Cent. Bull., 1, 63.

Darl, J. L. C., and Buchanan, J. (1962). Lancet, 2, 8.

Epstein, E. J., Coulshed, N., McKendrick, C. S., Clarke, J., and Kearns, W. E. (1966). Brit. Heart 7., 28, 546.

Escher, D. J. W. (1967). Amer. Heart f.; 74, 126.

Frei, E. H., Driller, J., Neufeld, H. N., Barr, I. Bleiden, L., and Askenazy, H. M. (1966). Med. Res. Eng., 5, 11.

Freidberg, C. K., Donoso, E., and Stein, W. G. (1964). Ann. N.Y. Acad. Sci., 111,835 .

Friedberg, C. K. (1966). Diseases of the Heart. Philadelphia.

Gale, H. H., and Enfroy, H. L. (1959). New Engl. F. Med., 260, 1229.

George, M., and Greenwood, T. W. (1967). Lancet, 2, 739 .

Gilchrist, A. R. (1958). Scot. med. F., 3, 53 .

Godman, M. J., Lassers, B. W., and Julian, D. G. (1968). In preparation. Harris, A., and Bluestone, R. (1966). Brit. Heart f., 28, 631. Julian, D. G., Valentine, P. A., and Miller, G. G. (1964). Amer. J. Med.,

Kimball, J. T., and Killip, T. (1965). Amer. Heart 7., 70, 35.

Lassers, B. W., Anderton, J. L., Muir, A., George, M., and Julian, D. G. (1968). Circulation. In press.

Lawrie D M et al (1967). Lancet, $2,109$.

Levowitz, B. S., Ford, W. B., and Smith, J. W. (1960). F. thorac. cardiovasc. Surg., 40, 283.

Lown, B. (1967). In Cardiac Pacing and Cardioversion. Philadelphia.

Lown, B., Vassaux, C., Hood, W. B., Fakhro, A. M., Kaplinsky, B., and Roberge, G. (1967). Amer. F. Cardiol., 20, 494.

Malach, M. (1967). Amer. F. Cardiol., 20, 363.

Meltzer, L. E. (1967). In Cardiac Pacing and Cardioversion. Philadelphia.

Mittra, B. (1966). Lancet, 2, 1438.

Oliver, M. F., Julian, D. G., and Donald, K. W. (1967). Amer. J. Cardiol., 20, 465.

Parsonnet, V., Zucker, I. R., Gilbert, L., Rothfeld, E. L., Brief, D. K., and Alpert, J. (1967). Israel F. med. Sci., 3, 306.

Paulk, E. A., and Hurst, J. W. (1966). Amer. 9 . Cardiol., 17, 695.

Penton, G. B., Miller, H., and Levine, S. (1956). Circutation, 13, 801. Siddons, H., and Sowton, E. (1967). Cardiac Pacemers. Springfield,

Illinais.
Vogel, J. H. K., and Brammell, H. L. (1967). In Mechanisms and Therapy of Cardiac Arrhythmias, edited by L. S. Dreifus. New York.

World Health Organization (1959). Wld Hlth Org. tochn. Rep. Ser.. No. $168, \mathrm{p}, 18$.

Yoffa, D. (1965). Lancet, 2, 614.

Zoll, P. M. (1952). New Engl. \%. Med., 247, 768.

Zoll, P. M. (1967). Israel F. med. Sci., 3, 257. 